Vol. 4, No. 1, 2018

\author{
Maksym Bondarenko' ${ }^{1}$, Viktor Antonyuk ${ }^{2}$, Yurii Kovalenko ${ }^{3}$, \\ Maksym Rud ${ }^{4}$, Roman Haidash ${ }^{5}$ \\ ${ }^{1}$ Department of Instrumentation, Mechatronics and Computerized Technologies, Cherkasy State Technological \\ University, 460, boul. T. Shevchenka, Cherkasy, Ukraine, E-mail: maxxium23@ gmail.com \\ ${ }^{2}$ Department of Instrumentation Design and Engineering, National Technical University of Ukraine "Igor \\ Sikorsky Kyiv Polytechnic Institute”, 37, Peremohy Avenue, Kyiv, Ukraine, E-mail: vp@kpi.ua \\ ${ }^{3}$ Department of Physics, Cherkasy State Technological University, 460, boul. T. Shevchenka, Cherkasy, Ukraine, \\ E-mail: kovalenkoyi@ukr.net \\ ${ }^{4}$ Department of Cars and Technology Exploitation, Cherkasy State Technological University, \\ 460, boul. T. Shevchenka, Cherkasy, Ukraine, E-mail: hochspannung77@gmail.com \\ ${ }^{5}$ Department of Physics, Cherkasy State Technological University, 460, boul. T. Shevchenka, Cherkasy, Ukraine, \\ E-mail: kaf-physics@ukr.net
}

\title{
RESEARCH OF VOLT-AMPERE CHARACTERISTICS OF THE WIRE PIERCE ELECTRON GUN AT ELECTRON-BEAM MICROPROCESSING OF DIELECTRICS
}

Received: February 19, 2018 / Revised: May 29, 2018 / Accepted: June 26, 2018

(C) Bondarenko M., Antonyuk V., Kovalenko Yu., Rud M., Haidash R., 2018

\begin{abstract}
The article considers the basic energy characteristics of a wire Pierce electron-beam gun, which used for microprocessing of dielectric materials in vacuo. The aim of the work is to determine the optimal regimes of electron-beam microprocessing of dielectric materials by studying the volt-ampere characteristics of the wire Pierce electron-beam gun. In the methodical part of the scientific work, a technological experiment with electron-beam microprocessing of dielectric surfaces is proposed, and also identified and studied the operating modes of the Pierce electron-beam gun in depending on their energy characteristics. As a result, the analysis of the obtained results of electron-beam microprocessing of surfaces of dielectric materials makes it possible to increase the reproducibility of the results of such treatment in terms of purity and residual nanorelief by 18-25\%. The comparison of the results of experimental electron-beam microprocessing of dielectrics with the results of their laser processing made it possible to establish a decrease in the residual microroughness of the surface of the optical glass $\mathrm{K} 8$ by $17 \ldots 27$ times with electron-beam microprocessing and by 12-14 times with surface laser treatment. Wherein, surface laser processing does not allow to eliminate the undulation of the surface, which is related to the specificity of the interaction of the laser beam with the surface of the optical material, whereas, when processing by the ribbon-shaped electronic stream such undulation does not appear. Conclusions and analyzed data obtained in the article based on the results of experimental studies can be used to optimize the technological regimes of electron-beam microprocessing in the production of micro-optics products, integrated optics, microelectrooptics, nanoelectronics, etc.
\end{abstract}

Keywords: electron-beam microprocessing, Pierce electron gun, volt-ampere characteristics, micro-optics products, dielectric materials, atomic-force microscopy.

\section{Introduction}

The modern level of development of science and technology raises a number of requirements for the elements of high-tech equipment, among them: high reliability, miniature, precision and accuracy of their performance [1]. Particular attention is paid to products made from modern dielectric materials (optical glass, ceramics, composite and metamaterials), which have proved to be a reliable and sometimes nonalternative replacement for the traditional construction materials. Among the wide of nomenclature such 
dielectrics, it should be noted optical glass and ceramics, which have recently become more widely used in such industries as precision instrument making, precision engineering, information technology, aerospace construction, medicine, etc.

However, further miniaturization and expansion of functional properties of elements of products made of these materials, manufactured using traditional methods involving mechanical, chemicalmechanical and flame polishing methods, is limited by the presence of a defective near-surface layer, which significantly reduces the technical and operational characteristics of these products. The solution to this problem is in the high-precision processing of dielectric materials by modern high-energy methods.

Among promising methods of processing dielectric materials with the use of concentrated energy fluxes, proved himself the method of ribbon-shape electron-beam microprocessing [2], which allows not only to reduce the residual surface microrelief to units of nanometers, but also completely eliminate defective and fractured near-surface layers in the dielectric by melting of the surface to a depth of $10 \mu \mathrm{m}$. The tool of such processing is the ribbon-shape electronic stream, generated by a wire tungsten cathode of the Pierce electronbeam gun, the design and principle of operation of which are discussed in detail in the work [3].

\section{Formulation of the problem of scientific research}

As noted by the authors of [4], the electron-beam microprocessing method using the Pierce electronbeam gun with a wire cathode was used for surface polishing of silicate optical glass plates, which made it possible to obtain defect-free surfaces with residual irregularities up to $5 \mathrm{~nm}$ with complete elimination in them near-surface defect layer. Wherein, the mode of such processing was selected by experimental studies and can not be used for qualitative surface electron-beam microprocessing, for example, aspherical surfaces.

At the same time, in the works of the authors V. A. Vaschenko, G. V. Dudko, G. V. Kanashevich, A. T. Krishnan, V. G. Lisochenko, E. Micler and others [5-7] proposed and developed a method of controlled microprocessing of surfaces of various dielectric materials (optical glass, ceramics, composite materials, sapphire and others) by a low-energy ribbon-shape stream of electrons.

However, further development and improvement of the proposed method for the processing of dielectrics is limited by a number of unresolved questions. Basic problem for today is that modern methods for diagnosing the ribbon-shape stream of electrons do not allow the operational control and stabilization of the energy distribution in the electron beam. Therefore, the issue of operational diagnostics of the energy characteristics of a ribbon-shape electron beam is topical and can be solved by application of modern automatic control devices.

The main indicator of qualitative electron-beam microprocessing of dielectric materials is observance of the equability of the energy distribution law of the electronic tape and the stability of this distribution during the movement of the electronic tape along the surface to be treated. Using the methodic described in [8], by selecting of the geometric parameters of the Pierce electron-beam gun, is shown the possibility of obtain equable by distribution of energy of the ribbon-shape electron stream. Wherein, the deviation of the width of the electron beam relative to the size of its central part (and, correspondingly, the energy distribution of the electron tape) for distances of $10-40 \mathrm{~mm}$ from the electron beam gun to the surface to be treated did not exceed 2-5\%. However, this methodic does not allow to dynamically control the power distribution in the electronic tape, has a low stability (the temperature and time of cathode heating significantly increase its resistance, which leads to a decrease in the energy parameters of the electron beam), which leads to the need for manual correction of the electron beam current and accelerating voltage.

Therefore, it is relevant to study the energy-volt-ampere characteristics of the Pierce electron-beam gun to obtain a stable energy distribution of the electronic tape in the process of qualitative electron-beam microprocessing of dielectric materials.

The aim of the work is to determine the optimal regimes of electron-beam microprocessing of dielectric materials by studying the volt-ampere characteristics of the wire Pierce electron-beam gun. 


\section{Materials and methods of the research}

Experimental studies were carried out on the modernized vacuum unit UVN-71, which contains the Pierce electron beam gun (the diameter of the cathode is $0.4 \mathrm{~mm}$, the length of the cathode is $90 \mathrm{~mm}$, the length of the anode slit is $a=80 \mathrm{~mm}$, the width of the anode slit $b_{a}=2 \mathrm{~mm}$ ), which generates ribbon-shape electron stream of a $60 \mathrm{~mm}$ length. Performance characteristics of electron-beam gun: maximum cathode warm-up current $I_{f}=50 \mathrm{~A} \pm 15 \%$; range of accelerating voltages $U=1.5-12 \mathrm{kV} \pm 2-3 \%$; range of electron stream currents $I=50-500 \mathrm{~mA} \pm 1-5 \%$. The pressure in a vacuum chamber with electron-beam microprocessing is $p_{0}=(3-5) 10^{-4} \mathrm{~Pa}$ and recorded by the vacuum gauge VMB-8 (pressure measuring range $10^{0}-10^{-7} \mathrm{~Pa}$ ). The distance from the electron gun (the outer surface of the anode) to the surface treated was $H=40 \mathrm{~mm} \pm 0,1 \mathrm{~mm}$.

The experimental scheme of the research, shown in Fig. 1, makes it possible to correctly measure and investigate the volt-ampere characteristic of the wire Pierce electron-beam gun.

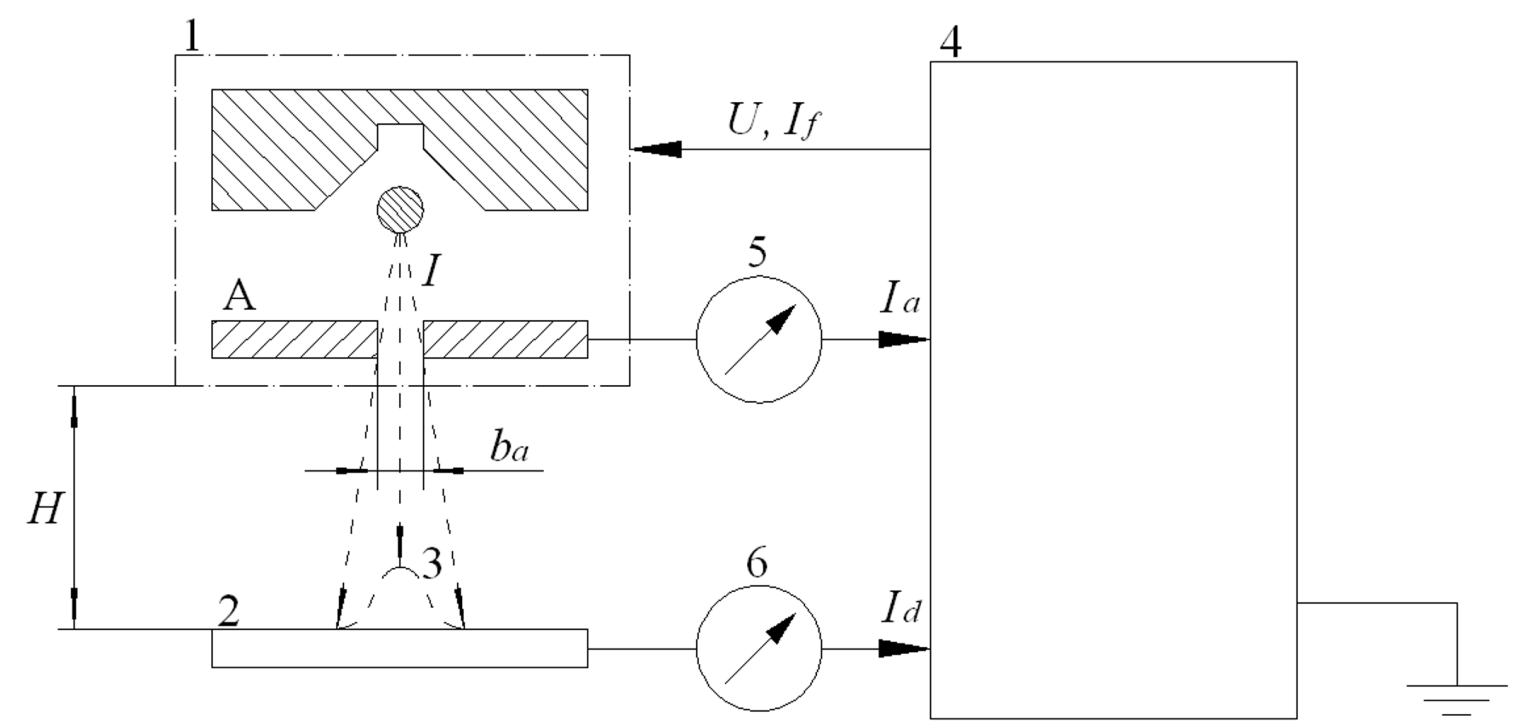

Fig. 1. The experimental scheme for determining the volt-ampere characteristic at the cathode of the Pierce electronbeam gun and on the dielectric plate: 1 -Pierce electron-beam gun; 2 - the dielectric plate; 3 -distribution of the electron stream of the ribbon-shape form along the surface of the dielectric material; 4 -controlled power unit of the electron-beam gun; 5, 6-multimeters for measuring current at anode and on dielectric material; A - anode;

$H$-distance from electron-beam gun to dielectric surface; $b_{a}$ - anode slit width; $U$-accelerating voltage; $I_{f}$-cathode warm-up current; $I$ - electron stream current; $I_{a}$ - current on the anode; $I_{d}$ - current on the dielectric

For the visual observation of the action of the electron stream, used the method of thermic-influens zones, described in work [8], arising on a plate of steel X6CrNiTi18-10 (DIN 17440) with a change in its surface structure as a result of heating and annealing.

The results of electron-beam microprocessing of dielectrics, which were carried out under optimal conditions, were compared with the results of laser processing, which was performed with a scanning laser beam (beam diameter $200 \mu \mathrm{m}$ ) on the "Diar-6" unit (manufactured by "Aramis", Cherkassy) by the following modes: radiation power $15 \mathrm{~W}$, scanning speed $500 \mathrm{~mm} / \mathrm{s}$, focal length $150 \mathrm{~mm}$.

Research of the microgeometry of the surfaces of optical plates after electron-beam microprocessing of surface laser processing was carried out with the "NT-206" (manufactured by: Microtestmachines Co., Belarus). Wherein, used a silicon probes "Ultrasharp CSC12" (manufactured by: Mikromasch Co., Germany). The device also includes a micropositioning system and Logitech's built-in optical long-focusing microscope (manufactured by Logitech Inc, USA), which allow selection of the desired area on the sample surface.

To increase the reliability of the results of the study, the microgeometry is measured in at least three random points on five identical samples, processed under the same regimes and separately taken for each type of processing. 


\section{Analysis of the results}

As a result of technological experiments to determine the distribution of the current of the electron beam at the anode and the dielectric material that acted as the processing object (optical glass K8), the dependence of the current of the electron beam $I$ on the accelerating voltage $U$ was obtained for various values of the width of the anode gap and the cathode warm-up current $I_{f}$, Fig. 2-4.

For visual observation of the equability of the energy distribution law of the electron tape along the surface to be treated, used the method of thermic-influence zones. The width, shape and intensity of these zones was determined from the center of the contrast band formed by the electron-beam and located on a plate of steel X6CrNiTi18-10 (DIN 17440) in an electron-beam gun, Fig. 2-4, $a$. The central part of the zones of thermal influence of maximum intensity corresponded to the maximum thermal effect of the electron-beam on the researched surface.

It was taken into account the fact that the intensity and uniformity of the distribution of the electron flux on the metal plate is more pronounced than on a plate with a dielectric material (for example, on an optical glass K8). At the same time, the width of the zones of thermal action on the dielectric is greater than the width of the zones of thermal influence on the conductor by 1.2-2.3 times with the same modes of electron-beam microprocessing.
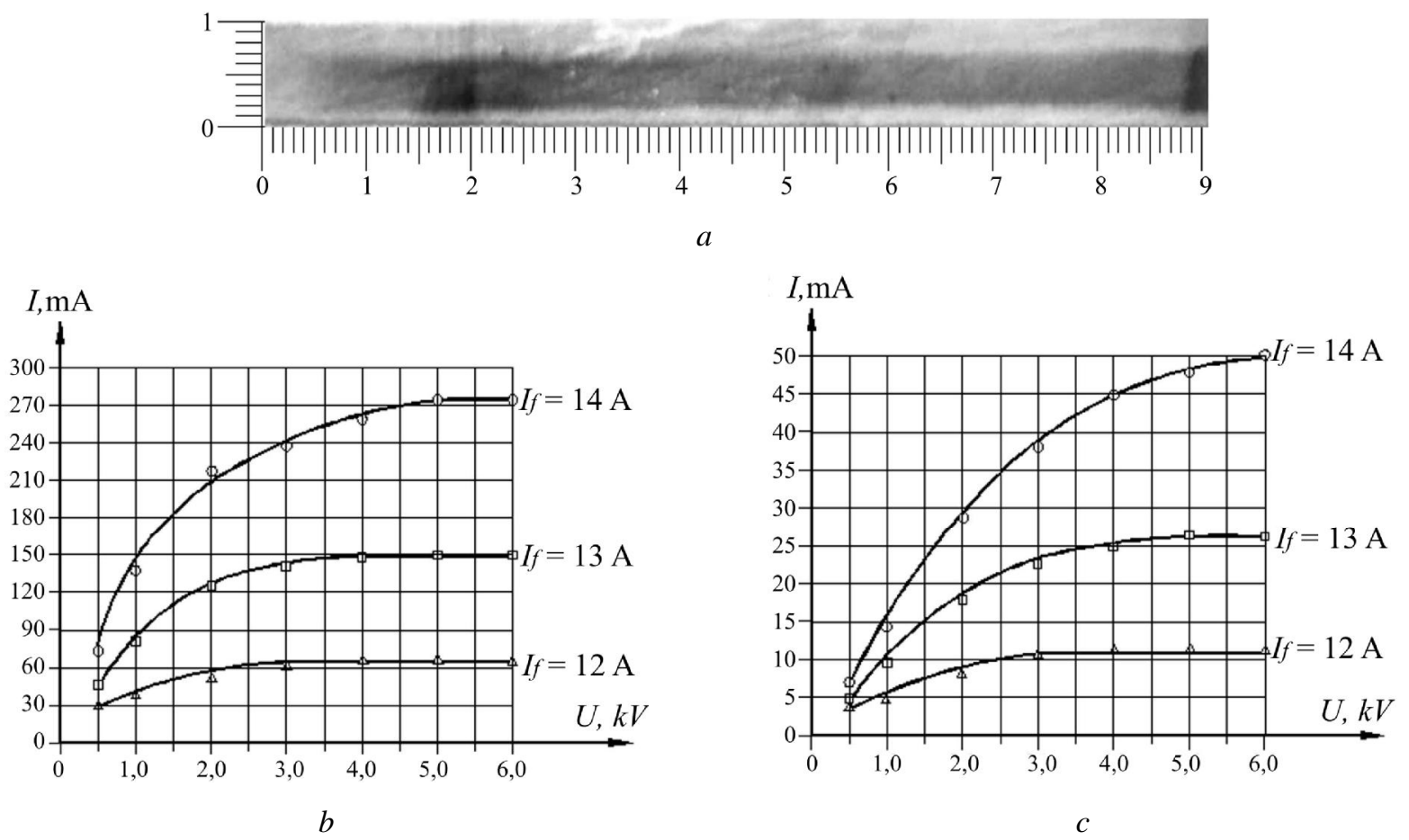

Fig. 2. A characteristic view of the zones of thermal action on the surface of a plate made of steel X6CrNiTi18-10 (DIN 17440) (a) from the action of the electron-beam and the dependence of the electron-beam current and on the accelerating voltage $U$ on the cathode $(b)$ of the Pierce electron-beam gun and on the plate of glass K8 (c). Anode slit width $b_{a}=2,0 \mathrm{~mm}$, the area of the imprint on the optical plate from the action of the electronic tape 4,0 $\mathrm{mm} \times 90 \mathrm{~mm}$

As can be seen from Fig. 2, with the optimal geometric parameters of the Pierce electron-beam gun, which were obtained in [8], namely: at the width of the anode slit $b_{a}=2.0 \mathrm{~mm}$, the dependence of the electron beam current on the accelerating voltage both on the cathode of the electron gun and on the glass plate has a high stability in the accelerating voltage range of 3-6 kV and processing current of 30-180 $\mathrm{mA}$ (at the anode) and 5-30 $\mathrm{mA}$ (at dielectric) at a cathode incandescence current up to $13 \mathrm{~A}$, which corresponds to the basic technological regimes of low-energy electron-beam microprocessing of dielectrics (including optical glass), which are characteristic for the second stage of thermic influence [9]. This corresponds to a structural modification of the surface layer of dielectrics at which the fractured and defective layers are completely melted, in result of which thereby forming a new structure. On this modification basics the main technological regimes of electron-beam microprocessing of products from optical glass. 
For comparison, Figures 3 and 4 show the volt-ampere characteristics for the width of the anode slit $b_{a}=1,5 \mathrm{~mm}$ (Fig. 3) and $b_{a}=3,0 \mathrm{~mm}$ (Fig. 4).

Fig. 3 shows the volt-ampere characteristics at the cathode of the electron gun and on the K8 glass plate at the value of the anode slit $b_{a}=1.5 \mathrm{~mm}$. The results of the research of these characteristics indicate a high stability in the accelerating voltage range of 3-6 kV and processing current of 30-300 mA (at the anode), whereas on the dielectric the stable value of the accelerating voltage is observed only in the range of processing current values 5-15 mA, which corresponds only to the electron-beam microprocessing regimes for the first stage of thermic influence, which is characterized by heat treatment of surfaces, which is carried out without the creation of a liquid phase [9].
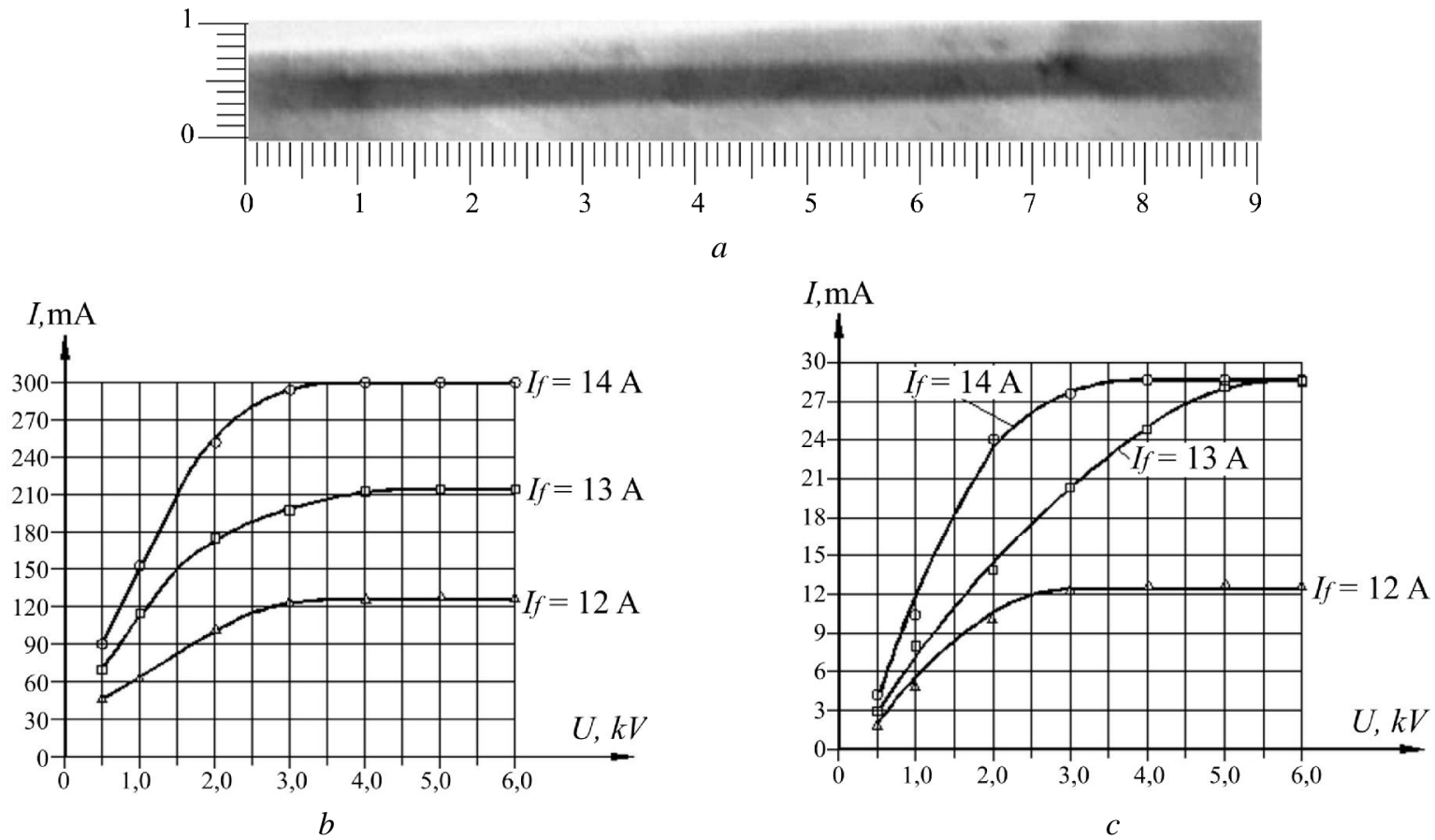

Fig. 3. Characteristic view of the ZTA on the surface of a plate of steel X6CrNiTi18-10 (DIN 17440) (a) from the action of the electron beam and the dependence of the current of the electron beam I on the accelerating voltage $U$ on the cathode (b) of the Pierce electron-beam gun and on the plate of glass $K 8(\mathrm{c})$. The width of the anode slit $b_{a}=1,5 \mathrm{~mm}$, the area of the imprint on the optical plate from the action of the electronic tape 2,7 $\mathrm{mm} \times 90 \mathrm{~mm}$

At the same time, at a value of $b_{a}=3,0 \mathrm{~mm}$ (Fig. 4), high stability, as in the case of $b_{a}=2,0 \mathrm{~mm}$ (Fig. 2), is observed in the accelerating voltage range 3-6 kV and the filament current of the cathode $I_{f}=12-14 \mathrm{~A}$. Wherein, the current of the electron beam at the anode lies in the range of values $\mathrm{I}=30-300 \mathrm{~mA}$, while on the dielectric the value of the processing current increases to $I_{d}=16-70 \mathrm{~mA}$, which corresponds only to the electron-beam microprocessing regimes for the third stage of the thermic influence, under which there is intense evaporation and boiling of the substance of the surface layer of optical glass, and its practical use is of little prospect and extremely limited [9].

The energy regimes of processing that were obtained as a result of the research of the volt-ampere characteristic of the wire Pierce electron-beam gun were used for surface reflow of $\mathrm{K} 8$ optical glass plates. Based on the results of the electron-beam microprocessing of dielectrics under optimal conditions, they were compared with the results of laser processing, revealed a decrease in the residual microroughness of the surface of the optical glass $\mathrm{K} 8$ from $40-110 \mathrm{~nm}$ to $1.5-6.5 \mathrm{~nm}$ with electron-beam microprocessing and up to $3.3-7.8 \mathrm{~nm}$ with surface laser processing, Fig. 5 [10].

Wherein, as can be seen in Fig. 5, the waviness was observed on the surfaces of the plates that were processed by the scanning laser beam. The increase in the power of laser radiation with a simultaneous increase in the focal length increases the undulation, which is probably due to the increase in the viscosity of the dielectric amorphous material in the air. A further increase in the laser radiation power from $15 \mathrm{~W}$ to $25 \mathrm{~W}$ leads to the formation of microcracks on the optical surfaces with further destruction of the surface. 

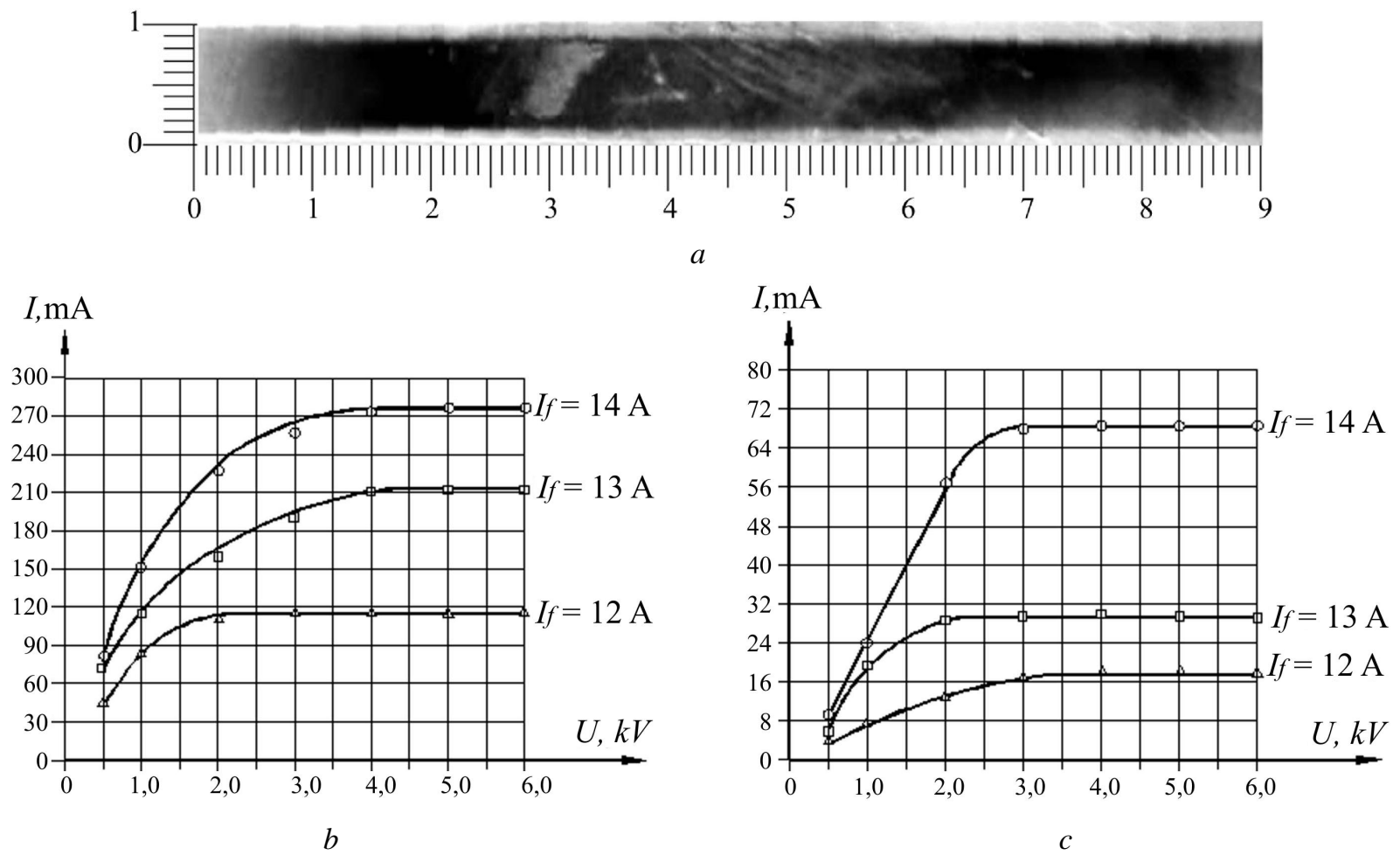

Fig. 4. Characteristic view of the zones of thermal action on the surface of a plate of steel X6CrNiTi18-10(DIN 17440)(a) from the action of the electron beam and the dependence of the current of the electron beam I on the accelerating voltage $U$ on the cathode $(b)$ of the Pierce electron-beam gun and on the plate of glass $K 8(c)$. The width of the anode slit $b_{a}=3.0 \mathrm{~mm}$, the area of the imprint on the optical plate from the action of the electronic tape $6.0 \mathrm{~mm} \times 90 \mathrm{~mm}$

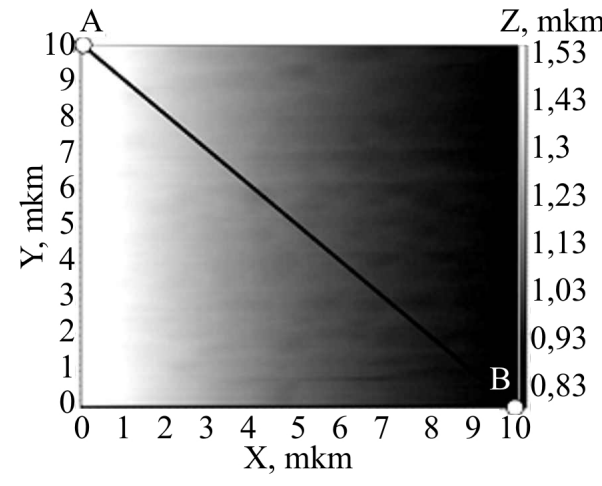

$a$

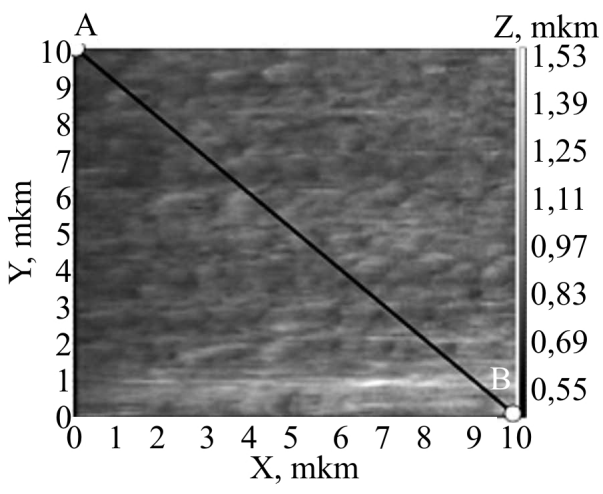

$b$

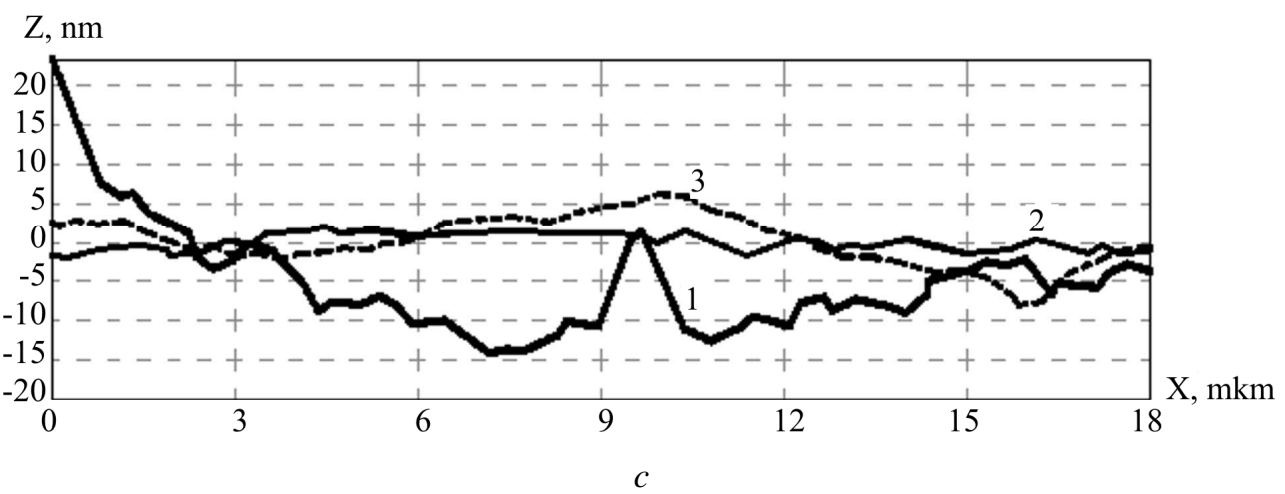

Fig. 5. The microgeometry $(a, b)$ and the profile along the A-B line $(c)$ of the surface area $(10 \times 10 \mu m)$ of the K8 glass plate, which was processed by the electron-beam $(a)$ and the scanning laser beam $(b)$ : 1 - the initial surface profile;

2 - surface profile processed by the electron-beam; 3 - surface profile processed with a scanning laser beam 


\section{Conclusions}

1. Researched the operation modes of the Pierce electron-beam gun depending on its energy characteristics. It is shown that with the width of the anode slit $b_{a}=2.0 \mathrm{~mm}$, it is possible to realize the basic technological regimes of low-energy electron-beam microprocessing of dielectrics (including optical glass) corresponding to the second stage of thermic influence, while a decrease and increase in the value of $b_{a}$ limits the range of technological regimes for the first and for the third stage of thermic influence, respectively.

2. The results of electron-beam microprocessing of dielectrics under optimal conditions with the results of their laser processing are compared, which made it possible to establish a decrease in the residual microroughness of the surface of the optical glass $\mathrm{K} 8$ from $40-110 \mathrm{~nm}$ to $1.5-6.5 \mathrm{~nm}$ in electron-beam microprocessing and up to 3.3-7.8 $\mathrm{nm}$ with surface laser processing. Wherein, surface laser processing does not allow eliminating the waviness of the surface, which is related to the specificity of the interaction of the laser beam with the surface of the optical material, whereas when processing by the ribbon-shape electron-beam, such waviness is not observed.

3. It is shown that electron-beam microprocessing of surfaces of dielectric materials by the example of plates made of K8 optical glass makes it possible to increase the reproducibility of the results of such microprocessing for the purity and residual nanorelief by $18-25 \%$.

\section{References}

[1] H. V. Kanashevych, et al., "Optoelektronika i mikrooptyka - perspektyvni haluzi nauky i tekhniky" ["Optoelectronics and microoptics are promising branches of science and technology"], Visnyk Cherkaskoho derzhavnoho tekhnolohichnoho universytetu [Collected scientific works of Cherkasy State Technological University], vol. 2, pp. 52-62, 2002. [in Ukrainian].

[2] M. O. Bondarenko, et al., "Vyvchennia umov utvorennia nanostruktur na poverkhniakh p'iezoelektrychnykh keramik pid diieiu strichkovoho elektronnoho potoku" ["Study of the conditions for the formation of nanostructures on the surfaces of piezoelectric ceramics under the action of a tape electron flux"], Visnyk Skhidnoukrainskoho natsionalnoho universitetu im.V.Dalia [Collected scientific works of V. Dalia East-Ukrainian National University], vol. 8 (162), part 2, pp. 30-34, 2011. [in Ukrainian].

[3] Yu. I. Kovalenko, et al., "Doslidzhennia ta formuvannia strichkovoho elektronnoho potoku dlia mikroobrobky poverkhon materialiv" ["Research and formation of tape electronic flow for microprocessing of materials surfaces"], Novi materialy i tekhnolohii v metalurhii ta mashynobuduvanni [ New materials and technology in metal and machinery], vol. 2, pp. 58-63, 2012. [in Ukrainian].

[4] Yu. I. Kovalenko, et al., "Modyfikatsiia nanoreliefu na optychnomu skli elektronno-promenevoiu mikroobrobkoiu" ["Modification of the nanorelief on optical glass by electron beam microprocessing"], Visnyk Cherkaskoho derzhavnoho tekhnolohichnoho universytetu [Collected scientific works of Cherkasy State Technological University], vol. 1, pp. 104-107, 2012. [in Ukrainian].

[5] E. Micler, Ching-Te Li, A. T. Krishnan, Changming Jin and Manoj Jain, "A charge damage study using an electron beam low k treatment", in Proceedings of the IEEE 2004 International Interconnect Technology Conference (IEEE Cat. No.04TH8729), Burlingame, CA, USA, 2004, pp. 190-192.

[6] N. V. Nikonorov, et al., "Electron-beam modification of the near-surface layers of photosensitive glasses", Tech. Phys. Lett., vol. 35, pp. 309-311, 2009.

[7] O. S. Druj, et al., "Electron beam transport in dielectric tubes", East Eur. J. Phys., vol. 1, pp. 70-73, 2014.

[8] M. P. Rud, et al., "The express-diagnostics of band electronic stream", Visnyk Cherkaskoho derzhavnoho tekhnolohichnoho universytetu [Collected scientific works of Cherkasy State Technological University], vol. 3, pp. 49-51, 2005.

[9] M. P. Rud, et al., "Vyznachennia rozpodilu hustyny strumu strichkovoho elektronnoho potoku pry obrobtsi optychnykh materialiv" ["Determination of the distribution of the current density of the tape electron beam in the processing of optical materials"], in Proc. V International scientific-practical conference "Dynamics of scientific research-2006", Dnipropetrovsk, Ukraine, 2006, vol. 7, pp. 45-47. [in Ukrainian].

[10] M. O. Bondarenko, H. V. Kanashevych and V. A. Vashchenko, "Optymizatsiia parametriv strichkovoho elektronnoho potoku za dopomohoiu zon termichnoho vplyvu" ["Optimization of the parameters of the tape electronic stream with the help of zones of thermal influence"], in Proc. I Int. Science and Technical Conference "Mechanical engineering and metal working - 2003", Kirovohrad, Ukraine, 2003, pp. 15-16. [in Ukrainian]. 